\title{
La justificación de decisiones judiciales
}

\author{
MARIA CRISTINA REDONDO \\ (CONICET-Argentina)
}

\section{Introducción}

Los jueces, por lo común, resuelven casos individuales mediante el dictado de sentencias que presuponen diversos tipos de decisiones. Por ejemplo, decisiones concernientes a actos personales del juez, a actos de terceros, a cuestiones normativas, a cuestiones de hecho, a deberes generales, a deberes individuales, etc. No todas ellas requieren una justificación explícita. La reflexión que quiero presentar en las siguientes líneas se refiere sólo a la justificación de la norma individual que pone fin al proceso judicial, para ello tomaré como paradigma la justificación de un deber impuesto a un tercero.

Algunas advertencias resultan fundamentales con relación a este tema. En primer lugar, es preciso no confundir una noción de justificación en sentido subjetivo -el acto de justificar (incluyendo su resultado verbal o escrito) - y la justificación en sentido objetivo - la relación existente entre los contenidos vinculados. A su vez, en ambos casos cabe distinguir una noción formal y una noción sustantiva de justificación. En tanto actos, la justificación formal y la sustantiva tienen idéntica manifestación externa: se realizan mediante la presentación de un argumento. Sin embargo, quien justifica en sentido formal sólo necesita suponer lógicamente un enunciado normativo como razón-premisa de dicho argumento, mientras que quien justifica en sentido sustantivo, acepta tal enunciado normativo como razón sustantiva para la acción. Esta última distinción se proyecta sobre la noción de razón. Quien intenta justificar formalmente invoca como fundamento lo que desde su pers- pectiva es una razón en el sentido de premisa formalmente apropiada. Quien pretende justificar en un sentido sustantivo, en cambio, invoca lo que desde su perspectiva es una adecuada razón sustantiva para la acción. En ambos casos el agente podría estar en un error. Es decir, aunque así lo acepte o lo crca, es posible que no haya invocado una premisa normativa o que esta no constituya una razón sustantiva,

El hecho de que el término «justificación» se refiera a una acción verbal o escrita, a un conjunto de enunciados resultantes o a una relación (formal o sustantiva) entre contenidos, exige especial cuidado en su utilización. Un estudio teórico no puede hacer uso de esta palabra con la ambigüedad que ella tiene en su empleo ordinario. Dentro de la filosofía jurídica la confusión de estos significados explica en muchos casos el error de algunas tesis que se presentan como críticas a la concepción positivista de la justificación en sede judicial. A ellas me referiré más adelante.

En la literatura actual sobre la justificación judicial es usual establecer la diferencia entre justificación interna y externa ${ }^{1}$. Desafortunadamente estos conceptos padecen una profunda imprecisión y no es claro qué distinción se pretende captar a través de ellos. Bajo dicha presentación se entrecruzan al menos tres cuestiones: i) sobre si las razones de la justificación judicial son de carácter interno o externo al sistema jurídico; ii) sobre si la obligación del juez incluye el deber de garantizar la corrección moral del argumento, y iii) sobre los tipos de argumentos - lógicos o no lógicos- adecuados a cada justificación. En otras palabras, en la distinción 
entre justificación interna y externa confluyen problemas diversos que sería beneficioso separar. Para evitar esta imprecisión dejaré de lado la distinción entre justificación interna y externa. En lo que sigue tendré en cuenta, por separado, algunos problemas vinculados a la justificación de la decisión final o norma individual dictada por el juez y a la justificación de las premisas normativas del argumento judicial.

\section{La justificación de la conclusión de la sentencia}

Conforme a una concepción positivista, la parte dispositiva de una sentencia, para estar justificada, debe poder inferirse formalmente a partir de las premisas invocadas por el propio juez. Es decir, la justificación de la resolución final del juez está asociada a la realización de un argumento práctico, en sentido lógico, en el que las disposiciones juridicas aplicables constituyen premisas normativas suficientes para justificar la conclusión. Esta propuesta positivista ha dado lugar a dos fuertes críticas. La primera de ellas, en la que no me detendré aquí, señala la inaplicabilidad de un argumento práctico, en sentido lógico. La segunda, que trataré de analizar en los párrafos que siguen, señala la necesidad de recurrir a normas morales para que la justificación sea válida.

Conforme a la segunda de las críticas aludidas, un correcto análísis de la decisión judicial muestra la implausibilidad de la tesis positivista sobre la separación entre derecho y moral. La idea central de csta crítica puede resumirse presentando el problema tal como lo propone Carlos Nino $^{2}$ : para justificar la imposición de un deber es preciso apoyarse cn normas. En una concepción positivista, las disposiciones jurídicas deben identificarse recurriendo a fuentes empiricas, es decir, hechos. A partir de hechos no podemos obtener normas, porque ello es un paso vedado por el denominado principio de Hume. Consecuentemente, las disposiciones juridicas, cuando se identifican siguiendo criterios positivistas, son entidades empíricas y no auténticamente normativas.

Lo dicho no debe llevarnos a pensar que conforme a esta crítica un argumento que finaliza en estas disposiciones juridicas es, por este motivo, inválido o incorrecto. En realidad es entimemático, porque presupone premisas auténticamente normativas. Éstas se hacen explícitas una vez que indagamos por las razones que llevan al juez a aceptar las premisas jurídicas. Éstas, en última instancia, siempre son morales. En concreto, conforme a este punto de vista, el positivismo no advierte que el desarrollo del argumento lógico tiene como presupuesto implícito la apelación a normas morales $^{3}$.

Según Carlos Nino, las disposiciones jurídicas o bien se aceptan porque se juzgan correctas, y en ese caso son indistinguibles de los juicios morales, o bien se aceptan porque tienen origen en determinados hechos sociales, por ejemplo, porque las promulgó un parlamento democrático. En este caso no son genuinas normas. En el ejemplo, del hecho que el parlamento diga que se debe hacer algo no se sigue que realmente se deba hacer, Para reconocerle el estatus de un deber es necesario presuponer una pauta normativa que haga relevante la acción parlamentaria, por cjemplo, cl principio segün el cual debe obedecerse a las autoridades democráticas. Pero éste, por sus características, es ya un principio moral ${ }^{4}$.

Pueden señalarse dos aspectos problemáticos en esta propuesta. Primero, la idea de que la aceptación de las disposiciones jurídicas por razones morales convierta el argumento lógico en un argumento moral. Scgundo, la tesis según la cual si una norma no es moral, entonces no es una norma genuina.

Respecto al primer punto, cabe destacar que la tesis del positivismo se refiere a la 
justificación formal de una decisión judicial, para la cual sólo se requieren las normas juridicas, las definiciones pertinentes y la descripción de los hechos que se deben juzgar. Esta reconstrucción no incluye ninguna tesis empírica acerca de las razones psicológicas por las cuales estas premisas de hecho se aceptan; tampoco es una propucsta prescriptiva acerca de las razones por las cuales se deberían aceptar. En contraste, la idea de aceptación que menciona Nino es la actitud psicológica de un individuo que se compromete con determinadas premisas. En este caso es la actitud del juez que se compromete con las normas que aplica. Aun si la sugerencia de Nino fuese verdadera, es decir, si fuese cierto que los jueces necesariamente aceptan las normas jurídicas por razones morales, de ello no se sigue que las normas jurídicas no sean suficientes para la justificación deductiva (formal) de la decisión final. $\mathrm{El}$ hecho de que la razón que explica la aceptación de las normas jurídicas sea, a su vez, la aceptación de normas morales no convierte a las normas jurídicas en normas morales, ni exige que el argumento para ser lógicamente válido se remonte a dichas normas. Del mismo modo en que, por cjemplo, si los axiomas de un sistema matemático se aceptan en virtud de razones (normas) religiosas, no por ello es plausible inferir que los argumentos matemáticos, basados en tales axiomas, deben incluir las normas religiosas, o que los axiomas matemáticos son indistinguibles de las mismas.

El segundo aspecto problemático mereccría una discusión independiente en la que no puedo entrar profundamente aquí. Sólo cabe destacar que la tesis positivista de las fuentes sociales o empíricas no implica que las normas sean entidades empíricas. La tesis de las fuentes sociales determina qué normas pueden pertenecer o ser válidas dentro de un sistema jurídico; pero no el estatus ontológico de las normas jurídicas. Asimismo, si por definición se decreta que todo enunciado deóntico, para expresar una norma genuina, debe expresar una razón moral, nos encontramos frente a una disputa verbal. La supuesta demostración que hace evidente la superioridad de la tesis de la conexión necesaria entre derecho y moral no es más que una petición de principio. Es decir, es una tesis presupuesta desde el inicio en virtud de la definición de «norma» de la que se parte. Si las únicas normas genuinas son morales el único concepto posible de justificación es el de justificación sustantiva. Sin embargo, esta propuesta normalmente no se concibe como una nueva reconstrucción conceptual de las nociones de norma y justificación, diferente de la reconstrucción positivista, sino como una refutación de esta última. Esta pretensión conlleva a la confusión de dos significados de «razón», uno como premisa formal de un argumento y otro como razón sustantiva para la acción. En la concepción de Nino nada es una razón-premisa apropiada, i. e. fundamento lógico adecuado, si no es a la vez una razón sustantiva para la acción. De este modo, el interés por la justificación moral sustantiva no constituye una ampliación del elenco de temas que merecen análisis respecto a la fundamentación de la decisión judicial, sino una reducción que pierde de vista la distinción entre los aspectos formales, por un lado, y sustantivos, por el otro. La crítica al positivismo necesita suprimir estas distinciones entre los aspectos formales y sustantivos, puesto que es la única forma de presentarse como una objeción. De lo contrario, debería admitir que está discutiendo sobre un problema diferente al que se estudia on una perspectiva positivista.

\section{La justificación de las premisas normativas de la sentencia}

Los problemas a los que me voy a referir a continuación son de una naturaleza dife- 
rente de los que se plantean respecto de la justificación lógica de la norma individual dictada en una sentencia judicial. La pregunta, en este caso, se refiere a si las razones-premisas invocadas son adecuadas en tanto razones sustantivas para la acción. Desde un punto de vista objetivo, la justifícación sustantiva de la decisión individual del juez exige la corrección material de las premisas utilizadas en su fundamentación. ¿La noción de sentencia judicial justificada supone el deber de justificar en este sentido?

Para evitar imprecisiones es importante decir explicitamente que:

I) El requerimiento de justificación sustantiva se entiende como un requerimiento de justificación moral, donde ala moral» debe entenderse en sentido ideal o crítico. Por tanto, es equivalente a una exigencia de justificación correcta.

II) Todas las nociones de argumento práctico que se citan - como estrategias para garantizar o alcanzar esta corrección- no son argumentos prácticos en sentido lógico. Son esquemas cuya aplica* ción permite cotejar y evaluar sustantivamente las razones en juego. Por ejemplo, a través de la implementación de un determinado procedimiento, o por las relaciones de fuerza o peso, o de medio a fin existentes entre ellas.

El requerimiento de una justificación sustantiva se fundamenta en la idea de que el argumento judicial debe apoyarse en premisas garantizadas. A su vez, esta idea constituye el corolario de un principio de racionalidad más general, según el cual toda justificación tiene que estar basada en razones a su vez justificadas ${ }^{5}$. Para este tipo de empresa la aplicación del modelo deductivo no es suficiente. $\mathrm{El}$ argumento práctico en sentido lógico sólo sirve a un concepto formal de justificación y no asegura que las premisas constituyan razones sustantivas para la acción.
En este apartado no me referiré a las premisas fácticas y sólo tendré en cuenta el problema de la justificación de las normas invocadas como base de la decisión judicial. El interrogantc acerca su corrección puede responderse a partir de diversos criterios. Algunas teorias jusnaturalistas clásicas sugieren, por ejemplo, su adecuación a un determinado código normativo (político, moral o religioso), o su utilidad instrumental con relación a determinados fines presupuestos como valiosos. En la filosofía moral actual la confianza en la razón práctica coloca el criterio de corrección en la propia idea de razonamiento práctico. Una condición necesaria (y en algunos casos suficiente) para garantizar la elección de las premisas correctas es que hayan sido obtenidas a través de un proceso racional de argumentación.

No en toda ocasión de dictar sentencia sc presenta la exigencia de justificación sustantiva de las premisas seleccionadas ${ }^{6}$. Por ejemplo, cuando las partes y el juez identifican el derecho aplicable mediante criterios interpretativos comunes y no hay conflictos entre las normas consideradas aplicables (o no se impugnan los criterios usados para resolverlos). Aunque la pregunta por la corrección de las premisas normativas puede formularse en cualquier ocasión, en la hipótesis de desacuerdo en la interpretación normativa es cuando de hecho se formula. Ante esta hipótesis hay dos interrogantes que se deben afrontar:

I) ¿Es posible establecer racionalmente cuál es la opción moralmente correcta entre dos propuestas en conflicto?

II) Cuando se presenta un conflicto en la identificación del derecho icuál es el criterio que deben utilizar los jueces para garantizar la corrección de las premisas escogidas?

I) La primera cuestión depende de la teoria metaética que se adopte. La posibilidad de responder racionalmente a la pregunta por la corrección moral de una 
norma se vincula, entre otras cosas, a una toma de posición acerca de la existencia de razones para la acción en sentido sustantivo. Al respecto pucden mencionarse tres posibilidades. En primer lugar, una postura escéptica que rechaza la existencia de ese tipo de razones. En la eventualidad de discrepancias acerca de la corrección de una norma el escéptico niega que el camino hacia la solución sea una búsqueda de razones. El escepticismo sostiene que el acto de elección no tiene carácter cognoscitivo. El desacuerdo referido a normas o a valores, es un desacuerdo emocional, y como tal debe resolverse. No puede dirimirse buscando una respuesta correcta o verdadera, porque no existe. Desde la perspectiva del escepticisno el problema que se presenta al juez respecto a la justificación material de las premisas no tiene una respucsta racional.

Una idea contrapuesta a la del escepticismo es la del realismo metafísico. Para esta concepción existen hechos normativos $y$, entre ellos, razones justificativas para la acción, independientemente de toda percepción y actividad humanas. Si es posible conocer este mundo normativo entonces es factible encontrar una respuesta correcta a los conflictos o desacuerdos prácticos que se plantean. La presencia de un conflicto es sólo manifestación del desconocimiento de una realidad y una jerarquía de razones objetivamente determinadas ? La búsqueda de solución a un conflicto de deberes plantea un problema epistémico. Una teoría normativa adecuada permitiría conocer cuál es la decisión correcta, la mejor o la más justa.

Entre estas dos posiciones extremas cabe una tercera vía. Conforme este punto de vista, el conflicto normativo podría ser abordado como un problema teórico. Es decir, es posible contar con un medio para solucionar conflictos normativos, de manera intersubjetivamente controlable, sin necesidad de creer en la verdad o falsedad de los enunciados acerca de razones sus- tantivas. El concepto de razón para la acción es un concepto teórico. Es una noción delineada en la teoría metaética para referirse a aquellos datos que fundamentan el discurso normativo. Por consiguiente, sus condiciones de existencia dependen de cómo sean concebidas en cada teoría metaética ${ }^{8}$. Para una corriente realista las razones existen independientemente de toda actitud humana. Para una posición escéptica las razones no existen, y para la propuesta que asumo en este trabajo, son entidades relativas a una tcoría normativa. Una razón pará la acción es el deber, o la permisión de actuar, establecidos y justificados por una teoría normativa ${ }^{9}$. La función de una tcoría normativa es fijar, con la mayor precisión posible, bajo qué condiciones se debe o está permitido realizar una determinada acción. Es decir, bajo qué condiciones existe una razón sustantiva para la acción. Estas razones deben servir como parámetro de crítica respecto de las pautas efectivamente aceptadas. Asimismo, deben permitir la resolución coherente de los conflictos entre deberes y permisiones, dentro de su alcance. Desde este punto de vista, es imposible individualizar una razón para la acción fuera de una teoría normativa. Identificar una razón para la acción supone utilizar alguna teoría normativa. Utilizar una teoría no implica aceptarla, del mismo modo que accptarla no implica creer que es verdadera 10.

II) La respuesta al segundo interrogante depende de la teoría de ética normativa que se asuma. Cuando se presenta un conflicto en la interpretación del derecho ¿cuál es el criterio que deben utilizar los jueces para garantizar la corrección de las premisas escogidas? Desde una ideología positivista la justificaciớn correcta es aquella que se conforma al derecho. Las normas juridicas deben aplicarse y obedecerse ${ }^{11}$. En presencia de un conflicto, la pregunta acerca de cuál es la mejor premisa debe responderse dentro del marco 
del sistema juridico. El juez es un funcionario de una institución social y la institución tiene sus reglas propias. El deber moral de apoyar la decisión en razones exclusivamente jurídicas es el axioma básico del positivismo ideológico y, por tanto, el principal criterio de corrección del argumento justificativo. Este compromiso con el sistema establecido implica que la justificación de la corrección de las premisas se apoyará, en última instancia, en un principio de autoridad. Una interpretación es la más adecuada por ser la más acorde con los principios instaurados. De esta posición ética puede extraerse una consecuencia importante. En ella se admite que el sistema juridico es un conjunto de pautas de justificación sustantiva. Esto es, las normas jurídicas son fuente de auténticos deberes, i. e. razones sustantivas para la acción.

Una concepción opuesta al positivismo ideológico es la del jusnaturalismo ideológico ${ }^{12}$. Desde su punto de vista sólo las normas justas deben aplicarse y obedecerse. El hecho de que una decisión se derive de las normas del sistema jurídico es irrelevante respecto de su carácter de razón sustantiva adecuada. Una decisión judicial está correctamente justificada sólo si se obtiene a partir de normas cuyo contenido es moralmente correcto. Todas las disposiciones jurídicas, incluyendo las normas individuales dictadas en sentencias judiciales, deben estar subordinadas a las pautas de la moral crítica. Sólo de ese modo adquieren carácter genuinamente justificativo. Conforme a esta ideología, independientemente de la dificultad que ofrezca el caso, el juez debe buscar las normas correctas sin limitarse al contexto del sistema jurídico. La necesidad de asegurar la adecuación material del argumento no se asocia a los casos dificiles, sino al propio concepto de justificación. La asunción de esta ideología tiene también una consecuencia digna de destacar. El derecho, si bien pretende hacerlo, no establece autén- ticos deberes: el éxito de esta pretensión está supeditado a la adecuación moral de su contenido.

En la teoría del derecho actual se defiende fundamentalmente una tesis moderada que sostiene la insuficiencia de la justificación juridica en los casos problemăticos. En esa dirección se encuentran la mayoría de las teorías de la argumentación. En este caso la corrección del contenido de una decisión se apoya en el respeto de un procedimiento de argumentación y no en la búsqueda de conformidad con un código de contenidos sustantivos. Estas escuelas confían en que el diseño de un esquema argumental adecuado determine la corrección material de la justificación. Está claro que se trata de un sentido no lógico de argumento. La ideología de las llamadas «teorias de la argumentaciốn» no es equiparable ni a la ideología jusnaturalista ni a la juspositivista. Un positivismo ideológico coherente debería admitir como correcta toda justificación apoyada en el derecho. El jusnaturalismo coherente se vería en la necesidad de admitir la irrelevancia absoluta del derecho ${ }^{13}$. Por lo general, las teorías de la argumentación intentan armonizar los principios de las dos ideologías extremas. Por una parte, admiten el deber de justificar la decisión judicial sobre la base de las normas jurídicas establecidas, para lo cual no descartan la utilidad del modelo deductivo de argumento práctico. Por otra parte, cuando existen conflictos en la determinación de las premisas jurídicas admiten la apelación a la moral como criterio último de resolución del conflicto $\mathrm{y}$, por tanto, como criterio para determinar cuál es la premisa correcta. Bajo el título de «teorías de la argumentación» se agrupan propuestas normativas con características muy diferentes. Desde esta perspectiva, el fundamento de la conexión necesaria entre la justificación jurídica y la justificación moral se encuentra en un rasgo atribuido a todo razonamiento involucrado en una 
justificación: el carácter unitario. Esta peculiaridad, se afirma, es la que pasa por alto el positivismo cuando admite que el argumento justificativo judicial puede finalizar correctamente en una premisa jurídica. La tesis positivista fragmenta el razonamiento y viola una de las reglas fundamentales de la argumentación práctica. Según Carlos S. Nino, el principio de unidad del razonamiento práctico constituye el «teorema fundamental de la filosofía juridica» ${ }^{14}$. El próximo apartado lo dedicaré a su discusión.

\section{El principio de unidad del razonamiento práctico}

Conforme destaqué anteriormente, una de las tesis del positivismo juridico afirma que la justificación judicial es una justificación formal a partir de premisas juridicas. En contra de esta posición se sostiene que la justificación judicial no puede ser otra que una justificación sustantiva, y que en virtud de la unidad del razonamiento práctico ella se apoya necesariamente en premisas morales.

En primer lugar es equívoco hablar de un eprincipio de unidad del razonamiento práctico», ya que esta formulación recibe distintas interpretaciones ${ }^{15}$. Conforme a aquella que lo hace relevante en este contexto, se trata de una tesis metaética que involucta, al menos, un compromiso con las dos siguientes ideas: I) una concepción general de racionalidad, conforme a la cual existe una jerarquía entre las diversas pautas justificativas existentes, y II) la existencia de un conjunto de normas morales constitutivas del último peldaño en el orden jerárquico de pautas de justificación.

Conforme a la idea de unidad, si el argumento que fundamenta un deber es correcto, lo es en un único sentido. Esto no supone ignorar la existencia de distintos tipos de discursos prácticos, por ejemplo, el discurso político, el jurídico, el religioso, etc.
Sólo que todos estos discursos se consideran integrados por medio de un conjunto de pautas últimas, a las que se concede el rango de moral ideal o verdadera. Bajo esta hipótesis, la corrección del argumento del juez no puede relativizarse al ámbito jurídico. Esto significaría admitir un punto de vista parcial o insular, y con ello el fraccionamiento del razonamiento práctico.

La mayor parte de los filósofos jurídicos preocupados por el tema de la justificación judicial acepta explicitamente este principio de unidad ${ }^{16}$. En general, están de acuerdo en sostener que el fraccionamiento constituye un error que comete el positivismo jurídico, y dicho error es síntoma de suna profunda incomprensión acerca de las reglas formales a que está sometido nuestro razonamiento práctico» ${ }^{17}$.

Es interesante destacar que en todas las interpretaciones que pueden ofrecerse de este principio la posibilidad de llegar a la moral como patrón unificador del razonamiento del individuo se apoya en una definición de «moral» como conjunto de reglas últimas. Esto es, en la atribución de calidad moral a los principios que ocupen el rango más alto dentro de la escala de preferencias o de pautas aceptadas ${ }^{18}$. Una vez que se define la moral por su carácter último necesariamente la moral constituye el último tribunal unificador del argumento práctico. El problema es que bajo esta interpretación la palabra «moral» está desprovista de todo contenido, y el principio de unidad del razonamiento práctico bajo los dictados de la moral es vacuo. Su invocación se explica sólo por el efecto emocional positivo que conserva. Afirmar: «la última instancia de justificación es moral" es equivalente a afirmar: «la última instancia de justificación es la última instancia de justificación".

Caben dos formas de entender la idea de unidad. La primera de ellas hace referencia a un requisito de unidad sistemática y da lugar a una versión débil del principio de unidad del razonamiento práctico. Este 
requisito garantiza que, dentro de una determinada concepción normativa, aun cuando ella incluya pautas de distinto tipo (por ejemplo morales, jurídicas, políticas, etc.), la pregunta por la corrección de un razonamiento práctico tendrá una respuesta univoca. Esto es, en última instancia debe haber una sola forma válida de juzgar un argumento práctico. Dicho de otro modo, toda concepcion normativa debe estar articulada de modo tal que, consideradas todas las cosas, o bien se debe 0 bien no se debe hacer $x$. El problema reside en que esta noción sistemática de unidad no excluye la posibilidad de coexistencia de múltiples concepciones normativas. Y algunas de ellas establecen que en determinadas circunstancias hay más de una perspectiva correcta para evaluar una situación. Ello sucede, por ejemplo, cuando se admite la legitimidad de ciertas razones excluyentes ${ }^{19}$. En este sentido el principio de unidad no obsta a que una concepción normativa sistemáticamente unitaria admita el fraccionamiento del razonamiento en el siguiente sentido: en una misma situación puede estar justificado jurídicamente hacer algo diferente de lo que está justificado hacer consideradas todas las cosas 20 .

Asimismo, aun cuando se niegue la posibilidad antes mencionada y se insista en que toda concepción normativa se asienta en una ủltima instancia de principios que unifican el juicio acerca de la corrección de un argumento, el fraccionamiento no queda descartado. Si dicho conjunto de principios es diferente en cada concepción, reaparece la pluralidad de los marcos de evaluación. Esta vez el fraccionamiento no es interno a una concepción normativa, sino que proviene de la existencia de una pluralidad de concepciones normativas. Los críticos del positivismo no pueden objetar la tesis de la suficiencia de la justificación jurídica sustentándose sólo en la idea de unidad sistemática de distintos tipos de discursos normativos bajo un con- junto de principios últimos. Para demostrar el error del fraccionamiento es necesario demostrar que también es un crror consentir la existencia de una pluralidad de puntos de vista igualmente correctos. Consentirlo implicaría que, desde el punto de vista metaćtico, serían admisibles distintos, e igualmente válidos, parámetros de evaluación de los argumentos prácticos. Para evitar esto es necesario sustentar una idea fucrte de unidad y exigir: I) que el conjunto de principios últimos sea también único, y II) que dentro de ese conjunto único no haya pautas que, siendo incompatibles, tengan igual rango o sean incomparables. En otras palabras, es necesario postular, a nivel metaético, la existencia de una única forma válida de justificación. Este requerimiento metaético de unidad tiene como consecuencia inevitable cl compromiso con la existencia de razones independientes de toda construcción teórica. Ello es así ya que, si se admite que las razoncs que avalan la concepción correcta dependen de construcciones teóricas, la pluralidad reaparece. El fraccionamiento justificativo con el que el positivismo jurídico se compromete constituye un error sólo bajo la presuposición de que existe una única concepción normativa correcta. Ello exige que el principio de unidad se vincule a una idea que usualmente no se enuncia explicitamente. En otros términos, los dos elementos antes mencionados: I) la existencia de una jerarquía entre las diversas pautas justificativas existentes, y II) un conjunto de normas morales que forman el último peldaño en esa jerarquí, no agotan el contenido del principio de unidad en sentido fuerte. Ellos sólo garantizan la unidad sistemática de cada concepción normativa, pero no la unidad de concepciones normativas.

La defensa de un postulado de unidad en sentido fuerte no implica que el conjunto de pautas de justificación correctas ya haya sido identificado. Pero puesto que existe, hay un buen motivo para alentar 
la discusión y tratar de encontrarlo. Esta empresa tropieza con un obstáculo hasta ahora insalvable. Satisfechas determinadas condiciones, cada intento de individualizar los principios morales correctos constituye una teoría moral diferente. Toda teoría moral es la propuesta de un conjunto de pautas (criterios) de corrección de acciones. Ello torna necesario que a nivel metaético se cuente con algún criterio que permita establecer qué teoría moral propone las pautas realmente correctas. En este punto pueden destacarse dos fuentes de dificultades epistémicas. La primera dificultad se refiere a la aplicación del criterio correspondentista de verdad. Preguntarse por la verdad del conjunto de pautas (criterios) de corrección de acciones, esto es, preguntarse por la verdad de una teoría normativa es equivalente a preguntarse por cuáles son las razones existentes que hacen verdadera o falsa una teoria. La identificación de semejantes razones no puede depender, a su vez, de una teoría normativa. Esto conduciría a un razonamiento circular. Las razones tienen que ser independientes de toda tcoria, puesto que son las que permiten identificar cuál es la teoría correcta. Esta advertencia es importante. En muchas ocasiones las propuestas que asumen la idea de unidad del razonamiento práctico como tesis metaética contraria al fraccionamiento pretenden adoptar una posición constructivista respecto a la ontología de las razones morales objetivas. Esto constituye un error. Si las razones objetivas son los datos que permiten verificar o falsear las concepciones o creencias morales de los individuos, entonces dichas razones no pueden depender de dichas concepciones o creencias. En este sentido la idea de unidad objetiva del razonamiento práctico, sumada a una concepción correspondentista de la verdad, parece exigir la aceptación del realismo metafísico en el ámbito moral.

La segunda dificultad no está desvinculada de la primera. Dados los inconve- nientes que plantea el acceso al conocimiento de las razones morales, pueden sugerirse dos formas de solución. $\mathrm{O}$ bien el abandono de la concepción correspondentista de verdad, por ejemplo, la adopción de una concepción coherentista de la verdad moral. $O$ bien, directamente, la estipulación de las razones con las que los principios normativos deben corresponderse para considerarse correctos. La primera opción debe desecharse si se pretende garantizar la unidad en sentido fuerte. Si la única exigencia a nivel metaćtico fuese la verdad en el sentido de coherencia debería admitirse la posibilidad de que una pluralidad de concepciones satisfagan esa condición. La segunda opción es la que se adopta, por ejemplo, cuando se define lo «correctos como aquello que provoca el incremento de la felicidad general ${ }^{21}$. Dicha posición propone la felicidad general como la única razón justificativa, y sostiene que la verdad o corrección de un principio moral consiste en su capacidad instrumental para promoverla. Sin embargo, si la estrategia es argumentar a favor de una única fuente de justificación, existen diversos candidatos diferentes de la felicidad general. $A$ la luz de cada uno de ellos serán distintos los conjuntos de prin. cipios que resulten moralmente correctos. En pocas palabras, a nivel metaético aparece el mismo problema que surge al nivel de la ética normativa. Así como la existencia de múltiples teorías normativas exige contar con un criterio para decidir cuál de ellas es la correcta, también la existencia de diversas propuestas metaéticas exige algún parámetro que permita determinar cuál es la metaética correcta. En conclusión, aun si se presupusiese la existencia de un único conjunto correcto de criterios de validez de los argumentos prácticos, las limitaciones epistémicas para determinar identificar ese conjunto conducirian, inevitablemente, al fraccionamiento del razonamiento en sentido subjetivo y tornarian 
inaplicable la idea de unidad en sentido abjetivo.

El principio de unidad propuesto a nivel metaético no demuestra que la separación de la justificación jurídica de la justificación moral constituya un error, sino que lo postula. La idea de unidad es un axioma, y conforme a él hay un único concepto de corrección y de deber. El interrogante consiste en si, desde un punto de vista filosófico, resulta plausible la adopción de este axioma. Para tomar una posición al respecto es necesario tener en cuenta los compromisos y consecuencias ligados a esta interpretación del principio de unidad.

\section{La fundamentación del principio metaético de unidad}

El principio de unidad del razonamiento práctico no se refiere sólo al razonamiento psicológico de los agentes que justifican una decisión, sino a los esquemas válidos de argumentación. Es decir, a los argumentos en sentido objetivo. El teorema de la unidad objetiva del razonamicnto, en tanto concepción metaética, no se adopta como un dogma sin fundamentación. En uno de los últimos trabajos de Carlos $\mathrm{S}$. Nino puede encontrarse una reflexión explicita acerca de estos fundamentos ${ }^{22}$. Conforme a este autor, la defensa coherente de este principio lleva a una posición esencialista respecto del significado de «deber». Si se aceptase el carácter convencional de este concepto habria que aceptar la posibilidad de diversos sentidos en que algo puede ser debido. Sería factible contar con cuantos tipos de deberes se distingan convencionalmente, y ello se encuentra en contradicción con el principio de unidad ${ }^{23}$.

Para argumentar en favor de esta concepción el profesor Nino se refiere en primer término a la propuesta de Willard V. O. Quine en su impugnación a uno de los dos dogmas del empirisma ${ }^{24}$. En el tra- bajo de Quine se sugiere, metafóricamente, que el conocimicnto humano debe considerarse como una «ábrica construida por el hombre», «como un campo de fuerza cuyas condiciones-límite da la experiencias ${ }^{25}$. Dentro de este campo hay proposiciones básicas (que se encuentran en el centro del campo) y otras menos básicas (las que están en la periferia del campo, lindante con la experiencia). Una modificación en los valores de verdad de un enunciado supone la revalorización de todos aquellos otros que están lógicamente conectados con él. Según Quine, cualquier enunciado del sistema de conocimiento podria concebirse como verdadero o como falso, siempre que se efectúen los reajustes necesarios en los restantes enunciados del sistema. Por supuesto, cambiar un enunciado central exigirá muchos más cambios que los que requeriría la modificación de algún enunciado periférico.

Sobre esta base Carlos Nino propone una analogía: lo dicho respecto de las proposiciones lo aplica a los conceptos. Esto es, sostiene que en nuestra red de conocimientos hay conceptos más centrales que otros. Por ejemplo, nociones como las de deber y de justicia ocupan un lugar central en el campo del conocimiento práctico y constituyen el punto de partida común de diversas concepciones que compiten entre sí. Ahora bien, es difícil comprender por qué Nino utiliza la idea de Quine como un argumento en favor de una concepción esencialista del significado de kdeber" cuando en realidad ella parece sugerir lo contrario. Conforme a la analogía establecida, al igual que toda proposición, todo concepto debería poder revalorizarse con tal de que se lleven a cabo las modificaciones pertinentes en los conceptos vinculados. Esto sugiere que la elaboración de un concepto es una tarea teórica y que, por consiguiente, es posible contar con una pluralidad de propuestas plausibles. Por ejemplo, una teoría del Derecho como la de Hans Kelsen utiliza un concepto de 
deber diferente del que se usa en la teoria de Herbert Hart, y ambas difieren del concepto kantiano de deber moral. A su vez el concepto kantiano no coincide con el concepto de Hume. Parte del aporte de estas teorias es de carácter semántico. Sería un error afirmar que ellas se limitan a proponer distintas concepciones o contenidos de un mismo concepto de deber.

En segundo lugar, Carlos Nino invoca un argumento muy diferente del sugerido por Quine. Destaca como una característica del concepto de deber la semejanza que éste guarda con los conceptos referidos a clases naturales. Es decir, aquellos cuyas propiedades estân constituidas por leyes naturales. Esta analogía le permite suponer que las tesis esencialistas, sostenidas respecto a los conceptos de clases naturales, pueden hacerse extensivas al concepto de deber. A tenor de las teorias de Saúl Kripke e Hilary Putnam, los conceptos de clases naturales se refieren necesariamente a algo que no depende de una convención; por tanto, no puede alterarse a través de ellas. En estos casos los cambios de significado propuestos por las distintas teorías no son productos de una decisión arbitraria. En realidad constituyen un intento por avanzar en el conocimiento de algo que no depende de las construcciones teoricas ni de acuerdos tácitos expresados en el lenguaje.

Independientemente de los argumentos a favor o en contra del esencialismo conceptual lo que interesa destacar es que ésta es la concepción filosófica con la que se compromete el principio de unidad. Plantear la existencia de una analogía entre el concepto de deber y aquellos constituidos por propiedaces naturales no es una idea novedosa. El jusnaturalismo clásico defendía abiertamente el postulado de que todos los conceptos del ámbito del «deber ser» aluden a propiedades naturales dependientes de leyes inmutables. En todo caso, la sugerencia mencionada muestra la conexión entre la crítica actual al positi- vismo y el jusnaturalismo clásico. Tomar esta analogía al pie de la letra significaría retroceder a una polémica que el propio Carlos Nino considera totalmente superada respecto de otros conceptos. El problema no reside en la reapertura de la discusión esencialismo-convencionalismo, sino el retorno a la asimilación de conceptos del ámbito del «deber ser», a conceptos del ámbito del «ser». Esto es, la identificación de nociones que no designan entidades sometidas a leyes causales con nociones que sí se refieren a este tipo de entidades. Uno de los méritos del positivismo en este ámbito es haber mostrado lo desafortunado de esta asimilación ${ }^{26}$. Por otra parte, si la analogía no ha de tomarse al pie de la letra, no existe la razón por la cual cabría aceptar los argumentos esencialistas respecto al concepto de deber, del mismo modo en que no existe para los restantes conceptos de la teoría jurídica.

En resumen, la interpretación objetiva del principio de unidad del razonamiento práctico torna necesario el esencialismo respecto de los conceptos de deber, de corrección $\mathrm{y}$, sobre todo, de razón para la acción, que para esta concepción es primario respecto del de deber. Del mismo modo que el convencionalismo conceptual está supuesto a nivel metaético en la idea relativista del deber, el esencialismo conceptual está supuesto a nivel metaético en la idea de unidad del deber.

\section{Conclusiones}

Retomando la pregunta que dio lugar al análisis desarrollado: ¿qué tipo de justificación se exige al juez? ¿Qué concepto de justificación se tiene en cuenta al reconstruir la sentencia judicial como una decisión justificada? El único tipo de justificación cuya exigencia puede plantearse de un modo intersubjetivamente controlable es la justificación en sentido formal. 
Respecto a la justificación sustantiva en sentido subjetivo, no es posible comprobar si los jueces aceptan o creen en las normas que invocan como razones sustantivas para la acción. Aunque en virtud de convenciones lingüisticas existentes sea usual atribuir al juez el compromiso con las normas que utiliza, toda la tarea judicial puede llevarse a cabo sin que el jucz accptc o crea en las normas como razones sustantivas. La afirmación de que en virtud del principio de unidad del razonamiento práctico la justificación judicial es una especie de justificación moral tiene carácter retórico. Si la noción de unidad se interpreta en sentido débil, la afirmación es vacua, puesto que sólo significa que la justificación jurídica presupone ciertas premisas últimas que por esa única razón se llaman morales. Si la unidad se entiende en sentido fuerte es impracticable. Aunque existiesen razones objetivas externas a toda teoría (y conforme a ellas, un conjunto único de pautas de justificación sustantiva) es imposible exigir este tipo de justificación. Las dificultades epistémicas que se le presentarian al juez al momento de cumplir con su obligación de dar la justificación correcta son las mismas que se le presentarían a quien intentase evaluar si el juez cumplió o no con su obligación.

El rechazo del esencialismo y del principio de unidad no clausura la posibilidad de diseñar teorías normativas, i. e. teorías sobre las razones sustantivas para la acción, que permitan resolver conflictos prácticos. Sólo el consenso o el acuerdo respecto de una determinada teoría normativa permitiria brindar o criticar «objetivamente» una justificación sustantiva y, en su caso, exigir su cumplimiento.

\section{BIBLIOGRAFÍA}

Alexy, Robert, «On the Necessary Relations Between Law and Morality, Ratio Juris, vol. 2, núm. 2, 1989.
- Teoría de la argumentación jurídica. La teoria del discurso racional como teoria de la fundamentación juridica, Centro de Estudios Constitucionales, Madrid, 1989.

Atrenza, Manuel, Las razones del derecho. Teorías de la argumentación, Centro de Estudios Constitucionales, Madrid, 1991.

- "Logica y argumentación jurídica", en Javier Echeverría, Javier de Lorenzo y Lorenzo Peña (eds.), Calculemos... Matemáticas y libertad. Homenaje a Miguel Sánchez-Mazas, Editorial Trotta, Madrid, 1996.

Bayón Mohino, Juan Carlos, La normatividad del derecho: deber juridico y razones para la acción, Centro de Estudios Constitucionales, Madrid, 1991.

Bonbio, Norberto, «Iusnaturalismo y positivismo jurídico», en El problema del positivismo juridico, Fontamara, México, 1991.

- «Positivismo jurídico», en El problema del positivismo juridico, Fontamara, México, 1991.

Brink, David O., "Externalist Moral Realism», The Southem Journal of Philosophy, vol. 24, Suplemento, 1986.

CARAcciolo, Ricardo, «L'argomento della credenza morale», Analisi e dinitto, 1994.

CoHen, Jonathan, "Acceptance and Belief», Mind, 98, 1989.

DE PÁramo, Juan Ramón, «Razonamiento jurídico e interpretación constitucional», Revista Española de Derecho Constitucional, vols. 22-24, 1981.

Dworkin, Ronald, Law's Empire, Harvard University Press, Cambridge, Mass., 1986.

JäÄSKINEN, Nilo, «External Justification of Proposition in Legal Science», en E. Bulygin y otros (eds.), Man, Law and Modern Forms of Life, D. Reidel, Dordrecht, 1985.

Kelsen, Hans, "Causality and Imputation», Ethics, núm. 1, 1950. 
KLARKE, D.S., «Does Acceptance Entail Belief?», American Philosophical Quarterly, vol. 31, núm. 2, 1994.

Mackie, John L., «The Subjetivity of Values», en Geoffrey Sayre-McCord (ed.), Essays on Moral Realism, Cornell University Press, Ithaca, 1988.

Moore, Michael, Moral Realism as the Best Explanation of Moral Experience, Saturday Discussion Group of southern California Leagal and Political Philosophers, 1989.

Moreso, Navarro y Redondo, «Argumentación jurídica, lógica y decisión judicials, Doxa, núm. 11, 1992.

Nino, Carlos S, Introducción al análisis del Derecho, Astrea, Buenos Aires, 1984. - El constructivismo ético, Centro de Estudios Constitucionales, Madrid, 1989.

- Etica y Derechos Humanos. Un ensayo de fundamentación, Astrea, Buenos Aires, 1989.

- La validez del Derecho, Astrea, Buenos Aires, 1985.

- «Respuesta a J. J. Moreso, P. E. Navarro y M. C. Redondo», Doxa, núm. 13, 1993.

- Breve nota sulla struttura del ragionamonto giuridico», Ragion Pratica, 1993.
- Derecho, moral y politica. Una revision de la teoria general del derecho, Ariel, Barcelona, 1994.

Qunve, Willard Van, «Two Dogmas of Empiricism», en Paul Moser (ed.), $A$ Priori Knowledge, Oxford University Press, Oxford, 1987.

Raz, Joseph, Practical Reasons and Noms, (2. ed.), Princeton University Press, 1990. Traducida por Ruiz Manero, Razón práctica y nomas, Centro de Estudios Constitucionales, Madrid, 1991.

Richaros, David, $A$ Theory of Reasons for Action, Clarendon Press, Oxford, 1971.

Schauer, Fredrerick, "Easy Cases», California Law Review, núm. 58, 1985.

SMITH, Michael, «Realism», en Peter Singer (ed.), Ethics, Oxford University Press, Oxford, 1994.

Soper, Philip, A Theory of Law, Harvard University Press, Cambridge, 1984.

WRólewski, Jerzy, «Legal Syllogism and Rationality of Judicial Decision», Rechtstheorie, núm. 5, 1974.

- "Legal Decision and its Justification", en H. Hubien (ed.), La raisonament juridique, Actas del Congrcso Mundial de Filosofía jurídica y social, Bruselas, 1971.

\footnotetext{
1 Cfr. Jerzy Wrôblewski, «Legal Decision and its Justification", en $\mathrm{H}$. Hubien (ed.), La raisonament juridique, Actas del Congreso Mundial de Filosofía jurídica y social, Bruxclles, 1971, pp. 409-419. También «Legal Syllogism and Rationality of Judicia] Decision", Rechtstheorie, núm. 5, 1974, pp. 33-34.

${ }^{2}$ Cfr. Carlos S. Nino, Derecho Moraly Politica. Ura revisión de la teorla general del dercho, Ariel, Barcelona, 1994.

Sobre esta propuesta de Nino puede verse la discusión planteada en Moreso, Navarro y Redondo, «Argumentacion juridica, Jogica y decisión judicial», Doxa, núm. 11, 1992, pp. 247-26, y Carlos S. Nino, «Respuesta
}

a J. J. Moreso, P. E. Navarro y M. C. Redondow, Doxa, núm. 13, 1993, pp. 261-264.

- Carlos S. Nino, El constnutivismo ético, Centro de Estudios Constitucionales, Madric, 1989, p. 30.

${ }^{s}$ Pueden distinguirse un sentido fundacionalista $y$ un sentido coherentista de justificación en este sentido. Conforme al primero, habria un conjunto de normas últimas aevidentes», «aulojustificadas», que fundamentan los restantes enunciados normativos. En contraste, conforme a las teorfas coherentistas no existe tal conjunto de principios básicos. Un enunciado está justificado cuando es coherente con el resto de los enunciados normativos aceplados por un sujeto (teoráas de la coherencia positiva) o si no es incoherente 
con los mismos (teorias de la coherencia negativa). Por ejemplo Aulis Aarnio y Neil MacComick pueden calificarse como partidarios de una teoría coherentista positiva, Por su parte, Nilo Jăàskinen, siguiendo a John Pollock, intenta defender la aplicación de la versión negativa de la teoria de la coherencia. Cfr. Nilo Jâaskinen, "External Justification of Proposition in Legal Sciences, en E. Bulygin y otros (eds.), Man, Law and Modem Foms of Life, D. Reidel, Dordrecht, 1985, pp. 224-229.

- Cfr. Fredrerick Schaucr, «Easy Cases», California Law Review, núm. 58, 1985.

${ }^{7}$ No toda concepción realista afirma la existencia de jerarquias objetivas. El realismo metafisicu respecto de los hechos morales generalmente se define por un conjunto de tesis ontológicas, semánticas y epistémicas. La tesis ontológica sostiene que estos hechos existen y son independientes del pensamiento y de la acción humanos. La tesis semántica afirma que los enunciados y términos morales se refieren a estos hechos morales. Es decir, se compromete con una teoría correspondentista de la verdad. Por último la tesis epistemica se refiere a que es ponsible obtener conocimiento moral. Esto cs, es necesario para el realismo contar con una teoría de la justificación y del descubrimiento de las verdades morales, Cfr. Michael Moore, Moral Realism as d: Best Explanation of Moral Experience, op. cit., pp. 4-11. Tambiên Michael Smith, "Realism", en Peter Singer (ed.), Ethics, op. cit, pp. 171-173. John L. Mackie, aThe Subjectivity of Valuesm, en Geoffrey Sayre-McCord (ed.), Essays on Moral Realism, Corncll University Press, Ithaca, 1988, pp. 95-118. David $O$. Brink, "Externalist Moral Realism», The Southern Journal of Philosopiy, vol. 24, Suplemento, 1986, p. 24.

* Las condiciones que debe satisfacer uni propuesta para constituir una teoria normativa dependen de lo que establezca una teoria del conocimiento apropiada para este ámbito de problemas. La precisión de estos criterios de adecuación epistemológicos excede los limites de cste trabajo. En cualquicr caso, la concepción sobre las razones para la acción que aquí se sigue no implica que cualquier propuesta normativa constituya una teoría normativa, $i$. e. un conjunto de razones para la acción. Pero sí excluye la posibilidad de que haya una teoria normativa verdadera sobre la base de razones. Si so sostuviese tal posibilidad, deberia admitirse el realismo metafísico respecto de las razones.

- La idea de la relatividad de las razones respecto de una teoria no debe confundirse con la tessis que sostiene su relatividad respecto de un medio cultural o social. Por ejemplo, para una metaética comunitarista todo deber depende de una previa concepción de lo bueno, que a su vez es ininteligible fuera de una comunidad. Una razón para la acción, i. e. aquello que indica lo que se debe o se puede hacer, depende de la concepción comunitaria de lo bueno. Por el contrario, la posición que aquí se sostiene afirma que todo deber depende de una teoría, independientemente de que ella sea concebida como universalmente válida o restringida a un determinado grupo social. to Esta conclusión supone que la noción de aceptación no implica la de creencia. Crr. Jonathan Cohen, “Acceptance and Belief», Mind, 98, 1989. En contra de esta interpretación véase D.S. Karke, aDoes Acceptance Entail Belief?», American Philosophical Quarterly, vol. 31, nûtn. 2, 1994.

1 Respecto al positivismo como ideologia véase Norberto Bobbio, "Positivismo juridico», en El problema del positivismo juridico, Fontamara, México, 1991, pp. 46-55.

12 Cfr. Norberto Bobbio, "Jusnaturalismo y positivismo jurídicon, en El problema del positivismo juridico, op. cit, pp. $67-90$.

1s Este problema cstá concctado con la denominada «paradoja de la irrelevancia moral del Derecho y del gobierno». Si las normas juridicas coinciden con los juicios morales son superfluas, porque la decision se puede justificar directamente en las pautas morales. Si las normas juridicas no coinciden con esas pautas, carecen de legitimidad y deben descartarse para la justificación de la decisión judicial. Cfr. Carlos S. Nino, Ética y Derechos Humanos. Un ensayo de fundamen. tación, Astrea, Buenos Aires, 1989, p. 370.

14 Carlos Nino, «Breve nota sulla struttura del ragiothamento giuridicos, Ragion Pratica, 1993, p, 32.

is Cfr. Manuel Atienza, «Ĺgica y argumentación juridicaw, en Javier Echevertía, Javier de Lorenzo y Lorenzo Peña (cds.), Calculemos.. Matenaticas y libertad. Homenaje a Miguel Sánchez-Mazas, Editorial Tro tta, Matrit, 1996, pp. 229-238. En adelante, para aludir al uprincipio de unidad del razonamiento práctico", se harâ referencia, indistintamente, a la propuesta, a la idea o al teorema de unidad.

${ }^{16}$ La tesis de la unidad del razonamiento práctico está presupuesta en los trabajos de David Richards, Joseph Raz, Philip Soper, Manuel Atienza, Juan Ruiz Manero, Juan Carlos Bayón Mohino, Juan Ramón de Páramo y Carlos S. Nino, etc.

12 Cfr. Carlos S. Nino, La validez del Derecho, Astrea, Buenos Aires, 1985, pp. 64-65.

18 Al respecto véase la crítica de Caracciolo al trabajo de Garzón Valdés en Ricardo Caracciolo, "L'argomento della credenza morale", Aralisi e divtto, 1994, pp. 97-110.

19 Por ejemplo, Joseph Raz, Practical Reasons and Norms (2." ed.), Princeton University Press, 1990.

2* Según Joseph Raz, lo tipico de la presencia de una razón excluyente es que la misma acción puede juzgarse de dos modos, que conducen a resultados contradictorios. Pero, conforme a la tesis de Raz, si la razón excluyente es válida, siempre prevalece. Lo que debe hacerse teniendo en cuenta las razones excluyentes válidas es correcto aun cuando no coincida con la que debe hacerse, consideradas todas las cosas. Al respecta vease Joseph Raz, Practical Reason and Noms, op. cit. Cito la versión castellana traducida por Ruiz Manero, Razón próctica y nommas, Centro de Estudios Constitucionales, Madrid, 1991, pp. 46-51, y Postscriptum, pp. 229-231. 
2 Esta concepciön metaética corresponde a una posición naturalista objetivista que en ocasiones está asociada a la teoria normativa del utilitarismo. Cfr. Carlos \$. Nino, Iniroducción al andisis del Derecho, Astrea, Buenos Aires, 1984, p. 357.

22 Carlos S. Nino, Derecho, moral y politica. Una revision de la teoria general del derecho, op. cit.

* La discusión acerca de si corresponde adoptar una concepción esencialista respecto al concepto de deber plantea un debate de carácter semántico. Es decir, acerca do: la relación entre los conceptos y la realidad. Hay una forma diferente de argumentar a favor de la cxistencia de conceptos no convencionales que no es útil para respaldar la tesis de Nino. Este argumento distingue dos tipos de consenso reflejados cn cl lenguaje. Por una partc, acuerdos que se adoptan o se abandonan por el solo hecho de que otros individuos también lo hacen. Por otra parte, acuerdos sus- tentados por convicción, que se adoptan o se abandonan por tazones sustantivas, independientes del acuerdo general. Esta tesis no se refiere a la correspondencia entre lenguaje y realidad. No es un análisis de caräcter semántico, y en ese sentido no representa una posición a favor del esencialismo respecto de ciertos conceptos. En todo caso, significa una impugnación genérica a la plausibilidad del análisis semántico. Cfr. Ronald Dworkin, Law's Enpire, Harvard University Press, Cambridge, Mass., 1986, pp. 135-139.

${ }^{2}$ Carlos Nino, Derecho, moral y politica, op. cit, pp. $30-31$.

25 Willard van Quine, «Two Dogmas of Ermpiricism", en Paul Moser (ed.), A Priori Knowledge, Oxford University Press, Oxford, 1987.

3. Hans Kolsen, "Causality and Imputation*, Edhics, núm. 1, 1950, pp. 1-11. 